\title{
Simulasi Multi Protocol Label Switching Virtual Private Network (MPLS VPN) Dengan Virtual Local Area Network (VLAN) Menggunakan Router MIKROTIK
}

\author{
Bertha Euginia ${ }^{1}$, Theresia Ghozali ${ }^{1}$
}

\begin{abstract}
Abstract MPLS VPN with VLAN network is used to get fast, secure, and easily accessible communication .MPLS network will send packet data with label in header to the destination and VPN will limit the user who can access the network by VRF configuration.Routing protocol OSPF will divide to two areas, customer area and provider area. VLAN will be configured in switch and router CE1 so they can exchange data to workgroup and it will be safe because itis not broadcasted. MPLS VPN with VLAN simulation using Mikrotik router board and switch by measuring bandwidth. The result show that MPLS VPN with VLAN using less bandwidth than MPLS VPN
\end{abstract}

KEYWORDS: OSPF,mikrotik,MPLS, VLAN,VPN

ABSTRAK: Untuk mendapatkan komunikasi yang cepat, aman, dan mudah diakses digunakan jaringan MPLS VPN menggunakan VLAN. Jaringan MPLS akan mengirimkan paket sesuai dengan label yang ada pada header paket ke tujuan yang diinginkan dan VPN akan membatasi siapa pengguna yang berhak mengakses jaringan menggunakan konfigurasi VRF. Routing protokol OSPF dibagi dua daerah yaitu daerah customer dan provider. VLAN akan dikonfigurasi melalui switch dan router CE1 agar dapat saling bertukar data ke workgroup dan lebih aman karena tidak dikirimkan secara broadcast. Hasil pengujian menunjukkan bahwa MPLS VPN dengan VLAN menghasilkan bandwidth lebih kecil dibandingkan MPLS VPN tanpa VLAN

KATA KUNCI: OSPF, mikrotik, MPLS, VLAN, VPN

\section{PENDAHULUAN}

Di i zaman seperti ini banyak orang dan perusahaan yang membutuhkan komunikasi yang lancar, aman, dan mudah diakses. Misalnya komunikasi dalam suatu perusahaan. Suatu perusahaan besar yang memiliki beberapa cabang perusahaan dapat berkomunikasi dengan baik dengan cara membangun jaringan komunikasi menggunakan switching dan routing serta harus memiliki jaringan yang aman agar tidak mudah diakses oleh pihak yang tidak bertanggungjawab.

Upaya yang dilakukan untuk membangun jaringan yang baik dan aman adalah dengan membuat Virtual Private Network (VPN) melalui jaringan Multi Protocol Label Switching (MPLS). Melalui VPN, dapat mempermudah pengguna karena dapat mengakses dan menggunakan jaringan pada perusahaan dimana saja selama terhubung dengan internet dan penggunaan bandwidth yang rata. Selain menggunakan VPN, untuk mempermudah perusahaan yang memiliki banyak divisi maka suatu perusahaan memerlukan suatu jaringan Virtual Local Area Network (VLAN). VLAN dapat berfungsi untuk menghubungkan beberapa cabang menjadi workgroup atau suatu grup kecil sehingga dapat berkomunikasi dengan divisi lain dengan lancar, mudah, dan murah. Dengan VLAN dapat membuat penggunaan bandwidth menjadi efisien sehingga dapat menghindari bandwidth storm. Satu divisi perusahaan dengan divisi perusahaan lain tentu ada beberapa data yang bersifat rahasia dan tidak dapat dikirimkan secara broadcast ke seluruh divisi. Oleh karena itu, pada jaringan ini diperlukan MPLS dan VLAN agar dapat menentukan rute mana yang ingin dilewati, rute mana yang cepat untuk mengirimkan suatu informasi dan workgroup mana yang ingin kita kirimkan informasinya.

\section{MULTI PROTOCOL LABEL SWITCHING (MPLS)}

Multiprotocol Label Switching (MPLS) adalah teknologi penyampaian paket pada jaringan dengan cepat yang menggabungkan kelebihan dari sistem komunikasi circuit-switched dan packet-switched. Kelebihan circuitswitched adalah menentukan jalur berdasarkan label yang ada pada paket, sedangkan kelebihan packet-switched adalah memungkinkan jalur dapat dipakai oleh user lain[2]. MPLS dapat mengirimkan data dengan cepat, karena pada MPLS memberi label pada header paket. Label tersebut akan memuat informasi penting yang berhubungan dengan informasi routing sebuah paket

Prinsip kerja MPLS adalah pemberian label pada setiap paket yang ingin diteruskan ke tujuan. Pemberian label dilakukan untuk menentukan jalur pengiriman ke tujuan dan prioritas paket mana yang harus dikirim dahulu. Pemberian label dilakukan dengan menyelipkan label di antara header layer 2 dan layer 3 pada paket yang diteruskan. Struktur label MPLS ditunjukkan pada Gambar 1.

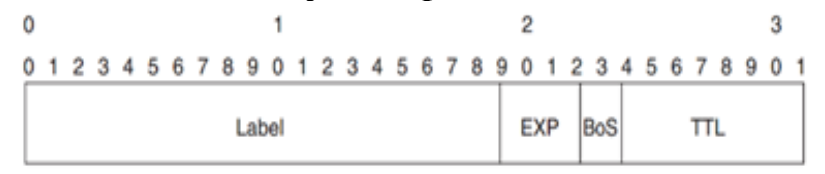

- Gambar 1 Struktur Label MPLS [1]

${ }^{1}$ Program Studi Teknik Elektro Universitas Katolik Atma Jaya 
Label MPLS terdiri dari 32 bit data dengan 20 bit pertama untuk nomor label, 3 bit untuk experimental (EXP), 1 bit untuk Bottom of Stack (BoS), dan 8 bit untuk Time To Live (TTL). Bit EXP berisi informasi kelas layanan. Bit pada BoS digunakan untuk mengetahui apakah terdapat label lain dalam suatu paket. Jika label BoS bernilai 1, maka terdapat lebih dari satu label pada paket, sedangkan jika BoS bernilai 0, maka hanya ada satu label pada paket. Bit TTL berisi informasi umur paket dan berapa kali paket dapat diteruskan. Bit TTL akan berkurang satu setiap paket melalui hop untuk menghindari terjadinya paket storms. Paket storms adalah paket yang tidak dapat diteruskan dan terjebak dalam loop, sehingga dapat menyebabkan kelebihan paket yang dikirim dan akhirnya paket akan crash atau tidak berhasil terkirim ke tujuan.

Berikut adalah komponen MPLS yang dapat dilihat pada Gambar 2, yaitu:

1. Label Switched Path (LSP)

Label MPLS terdiri dari 32 bit data dengan 20 bit pertama untuk nomor label, 3 bit untuk experimental (EXP), 1 bit untuk Bottom of Stack (BoS), dan 8 bit untuk Time To Live (TTL). Bit EXP berisi informasi kelas layanan. Bit pada BoS digunakan untuk mengetahui apakah terdapat label lain dalam suatu paket. Jika label BoS bernilai 1, maka terdapat lebih dari satu label pada paket, sedangkan jika BoS bernilai 0, maka hanya ada satu label pada paket. Bit TTL berisi informasi umur paket dan berapa kali paket dapat diteruskan. Bit TTL akan berkurang satu setiap paket melalui hop untuk menghindari terjadinya paket storms. Paket storms adalah paket yang tidak dapat diteruskan dan terjebak dalam loop, sehingga dapat menyebabkan kelebihan paket yang dikirim dan akhirnya paket akan crash atau tidak berhasil terkirim ke tujuan.

2. Label Switching Router (LSR)

Label Switching Router (LSR) merupakan MPLS node yang mampu meneruskan paket-paket layer 3

3. Label Edge Router (LER)

Label Edge Router (LER) merupakan MPLS node yang menghubungkan sebuah MPLS domain dengan node yang berada di luar MPLS domain

4. Label Distribution Protocol (LDP)

Label Distribution Protocol (LDP) berfungsi untuk mendistribusikan informasi yang ada pada label ke setiap LSR pada jaringan MPLS. Selain itu, LDP juga melakukan penempatan label awal (initial label) dan mengambil label MPLS dari paket (popped label).

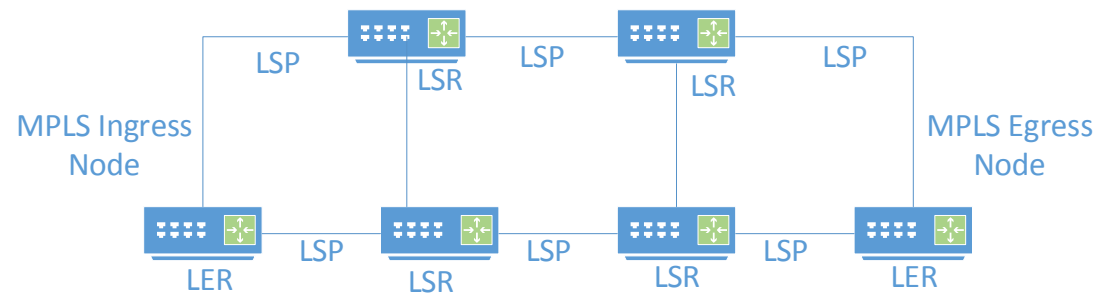

- Gambar 2 Komponen MPLS.

\section{MULTI PROTOCOL LABEL SWITCHING VIRTUAL PRIVATE NETWORK}

Virtual Private Network (VPN) adalah sebuah jaringan komputer dimana koneksi antar perangkatnya (node) memanfaatkan jaringan publik sehingga yang diperlukan hanyalah koneksi internet di masing-masing site Meskipun VPN menggunakan jaringan publik, keamanan dan kerahasiaan antar pengguna VPN dapat tetap terjaga karena VPN membentuk jalur virtual khusus yang hanya bisa diakses oleh pengguna VPN.

MPLS VPN merupakan jaringan VPN berbasis MPLS dimana komunikasi antar pengguna menjadi lebih aman meskipun menggunakan jaringan publik. Jaringan MPLS VPN dibagi menjadi empat jenis perangkat seperti Gambar 3, yaitu:

1. Perangkat Customer yaitu perangkat pada jaringan yang berhubungan langsung dengan pengguna jaringan.

2. Perangkat Customer Edge (CE) yaitu perangkat yang terletak di paling luar jaringan customer yang berhubungan langsung dengan perangkat Provider Edge (PE) untuk meneruskan setiap paket yang dikirim untuk customer.

3. Perangkat Provider Edge (PE) yaitu perangkat yang terletak di paling luar jaringan provider. Perangkat PE berfungsi untuk melakukan pemberian label paket, pertukaran informasi antar protokol routing, menerjemahkan informasi routing dari perangkat customer edge menjadi informasi VPNv4 route dan sebagai pembatas antara protokol routing pada customer dan provider.

4. Perangkat Provider yaitu perangkat yang terletak di pusat jaringan provider yang berfungsi untuk melakukan proses switching dan meneruskan paket MPLS menuju perangkat PE tujuan. [10] 


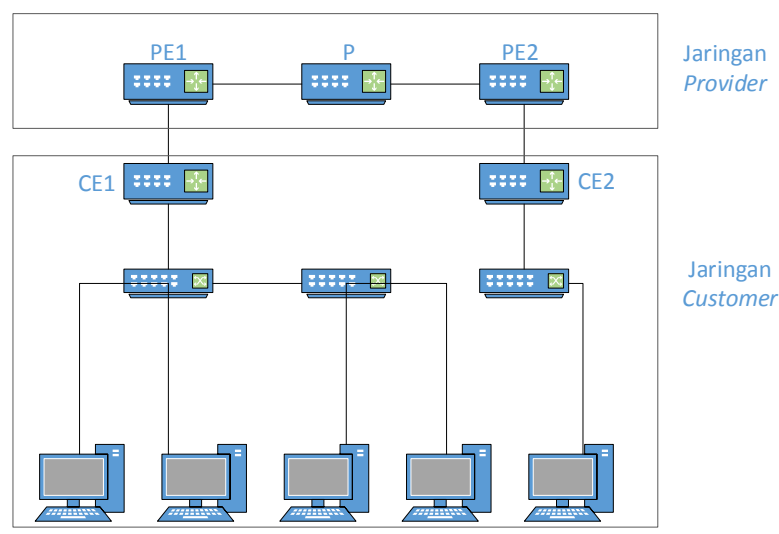

- Gambar 3 Jaringan MPLS VPN

Cara kerja MPLS adalah memberikan label pada header paket. Label MPLS berisi jalur yang akan ditempuh paket untuk sampai ke tujuan. Label yang berada pada ujung jaringan MPLS disebut Label Egde Router (LER). Label ini berguna untuk mencatat dan menganlisa paket sebelum masuk ke MPLS.

Setiap paket yang sudah diberi label akan masuk ke router berikutnya. Pada router provider edge (hop) akan dilihat informasi yang dibawa oleh paket mengenai hop berikutnya dan mengganti label paket (swap) dengan label baru yang ada pada router provider edge. Paket yang telah diberi label baru akan diteruskan ditujuan berdasarkan informasi routing dari router customer edge. Setelah sampai pada router customer edge tujuan akhir jaringan MPLS, label yang telah diteruskan dari provider edge akan dilepaskan dari header paket (рор).

\section{VIRTUAL ROUTING FORWARDING}

Virtual Routing and Forwarding (VRF) adalah teknologi yang memungkinkan beberapa tabel routing berjalan bersamaan pada suatu router dan pada waktu yang sama. Gambar 4 memperlihatkan jaringan VRF. Pada router Provider Edge (PE) harus dikonfigurasi terlebih dahulu menggunakan VRF agar dapat membentuk VPN. Alamat IP dari perangkat customer dan Customer Edge (CE) dicatat pada VRF. Setiap VRF memiliki data paket yang disimpan pada IP routing table untuk mencegah paket luar yang masuk ke dalam VPN dan mencegah paket didalam VPN yang akan diteruskan keluar dari VPN. [6].

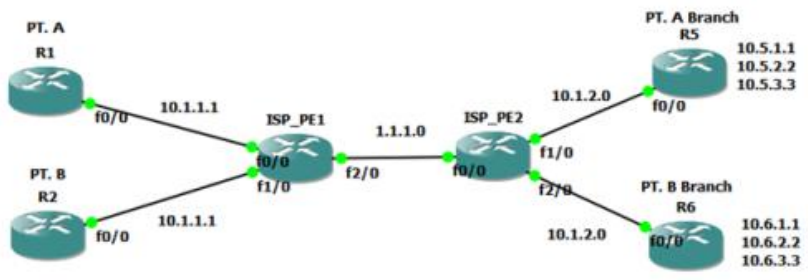

- Gambar 4 Jaringan VRF [5].

Komponen utama untuk dapat membentuk VRF adalah:

1. Route distinguisher membuat alamat IPv4 terdiri dari 32 bit menjadi 96 bit unique address. Format route distinguisher adalah autonomous system number:arbitrary number atau IP address:arbitrary number. Sebagai contoh, alamat IP tujuan adalah 192.168.10.0 dengan nomor autonomous system 100 dan jalur VPN 1. Setelah ditambahkan route distinguisher, alamat IP tujuan akan dikenali oleh jaringan sebagai 100:1 atau 192.168.10.0:1. Paket IP yang telah ditambahkan route distinguisher akan menjadi paket VPN-IPv4. Alamat VPN-IPv4 ini yang akan digunakan oleh MP BGP untuk meneruskan paket melalui MPLS.

2. Route target digunakan untuk menentukan route yang akan diimpor ke dalam VRF dan menentukan route yang akan diekspor dari VRF. Penambahan route target pada route distinguisher dilakukan saat terdapat customer yang memiliki dua atau lebih VPN. Sebagai contoh, route target-export 100:1 menandakan bahwa routing VRF akan diberikan kepada VRF dengan route distinguisher 100:1. Sedangkan, route-target import 100:1 menandakan bahwa VRF akan mengambil informasi routing dari VRF dengan route distinguiser 100:1. Dengan penggunaan route target, jaringan VPN hanya akan dapat diakses oleh VRF yang telah dikonfigurasi pada router. Gambar 5 menunjukkan bentuk alamat VPNv4. 
- VPN-IP address $=$ Route Distinguisher (RD) + IP address

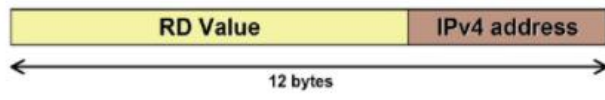

- 12 byte $=8$ byte +4 byte

- 96 bit

- Gambar 5 Bentuk alamat VPNv4.

BORDER GATEWAY PROTOCOL

Border Gateway Protocol (BGP) adalah salah satu jenis routing protocol yang berfungsi untuk mempertukarkan informasi antar Autonomous System (AS). Autonomous System (AS) adalah kumpulan dari jaringan-jaringan dalam satu administrasi yang mempunyai strategi routing bersama. BGP diperlukan untuk menerjemahkan alamat yang VPNv4 yang telah dirubah oleh VRF untuk membangun jaringan VPN dan BGP digunakan oleh router $\mathrm{PE}$ agar dapat terhubung dengan router $\mathrm{P}$.

\section{VIRTUAL LOCAL AREA NETWORK}

Virtual Local Area Network (VLAN) merupakan sekelompok perangkat pada satu Local Area Network (LAN) atau lebih yang dikonfigurasikan (menggunakan perangkat lunak pengelolaan) sehingga dapat berkomunikasi seperti halnya bila perangkat tersebut terhubung ke jalur yang sama, walaupun sebenarnya perangkat tersebut berada pada sejumlah segmen LAN yang berbeda. VLAN berada pada layer kedua pada OSI seven layer. Protokol umum yang paling sering digunakan adalah IEEE 802.1Q. 802.1Q berfungsi untuk membentuk jalur agar satu VLAN dengan VLAN lain dapat saling berkomunikasi[3]. Gambar 6 menunjukkan penambahab header untuk VLAN.

\begin{tabular}{|c|c|c|c|c|c|c|}
\hline Preamble & $\begin{array}{l}\text { Destination } \\
\text { MAC } \\
\text { address }\end{array}$ & $\begin{array}{l}\text { Source } \\
\text { MAC } \\
\text { address }\end{array}$ & Type & Payload & CRC/FCS & \\
\hline Preamble & $\begin{array}{l}\text { Destination } \\
\text { MAC } \\
\text { address }\end{array}$ & $\begin{array}{l}\text { Source } \\
\text { MAC } \\
\text { address }\end{array}$ & $\begin{array}{l}802.1 \mathrm{Q} \\
\text { header } \\
\text { (VLANID) }\end{array}$ & Type & Payload & $\begin{array}{l}\text { Recalculated } \\
\text { field } \\
\text { CRC/FCS }\end{array}$ \\
\hline
\end{tabular}

- Gambar 6 Penambahan header untuk Virtual Local Area Network (VLAN) [9]

VLAN dibagi menjadi 3 metode dalam penggunaannya, yaitu menggunakan port, MAC address, dan IP address. Semua informasi yang mengandung penandaan/pengalamatan suatu VLAN (tagging) disimpan pada suatu database. Jika VLAN yang akan digunakan menggunakan metode port, maka VLAN akan mengindikasi semua port yang digunakan ke dalam database. Switch atau bridge bertugas untuk bertanggung jawab menyimpan semua informasi port dalam database dan konfigurasi. [2]

\section{KONSEP PERANCANGAN}

Berikut adalah konsep perancangan berupa bagan alir perancangan simulasi MPLS VPN dengan VLAN pada Gambar 7

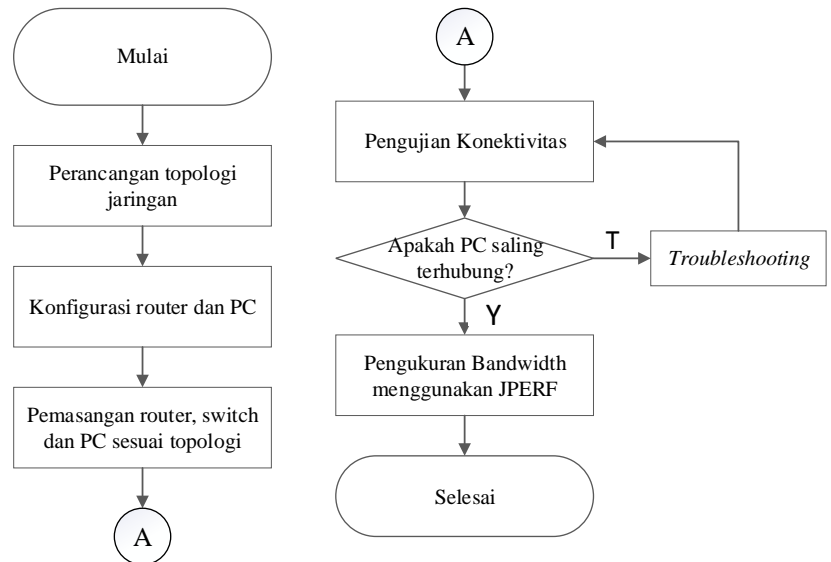

- Gambar 7 Bagan Alir Perancangan. 


\section{PERANCANGAN JARINGAN SIMULASI}

Perancangan simulasi jaringan Multi Protocol Label Switching Virtual Private Network (MPLS VPN) dengan Virtual Local Area Network (VLAN) akan dibagi 2 bagian yaitu area VPN dan VLAN. MPLS dan BGP akan dilakukan pada router provider dan router provider edge. Pada simulasi ini akan disimulasikan pada satu perusahaan A yang memiliki dua divisi yaitu VLAN. Topologi jaringan MPLS VPN dengan VLAN dapat dilihat pada Gambar 8.

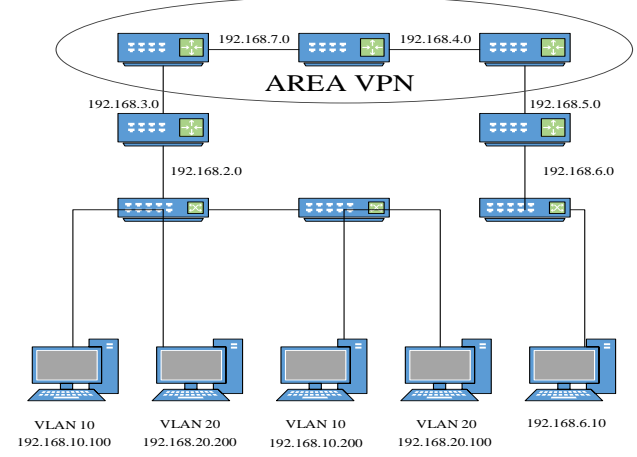

- Gambar 8 Topologi jaringan MPLS VPN dengan VLAN.

Pengaturan alamat IP address pada masing-masing router dan PC dapat dilihat pada Tabel 1 dan Tabel 2.

Tabel 1 Alamat IP masing-masing router

\begin{tabular}{|c|c|c|c|c|}
\hline Router & Ethernet 1 & Ethernet 2 & Ethernet 3 & Loopback \\
\hline CE1 & $192.168 .2 .6 / 24$ & $192.168 .3 .5 / 24$ & - & - \\
\hline PE 1 & $192.168 .3 .4 / 24$ & $192.168 .7 .7 / 24$ & - & 192.168 .10 .5 \\
\hline P & $192.168 .7 .8 / 24$ & $192.168 .4 .8 / 24$ & - & 192.168 .10 .6 \\
\hline CE2 & $192.168 .4 .7 / 24$ & $192.168 .5 .6 / 24$ & - & 192.168 .10 .7 \\
\hline
\end{tabular}

Tabel 2 Alamat IP masing-masing PC

\begin{tabular}{|c|c|c|c|c|}
\hline \multirow{2}{*}{ VLAN } & PC & IP Address & Subnet Mask & $\begin{array}{c}\text { Default } \\
\text { Gateway }\end{array}$ \\
\hline \multirow{2}{*}{10} & PC 1 & 192.168 .10 .100 & 255.255 .255 .0 & 192.168 .10 .1 \\
\cline { 2 - 5 } & PC 2 & 192.168 .20 .200 & 255.255 .255 .0 & 192.168 .20 .1 \\
\hline \multirow{2}{*}{20} & PC 3 & 192.168 .10 .200 & 255.255 .255 .0 & 192.168 .10 .1 \\
\cline { 2 - 5 } & PC 4 & 192.168 .20 .100 & 255.255 .255 .0 & 192.168 .20 .1 \\
\hline \multirow{2}{*}{-} & PC 5 & 192.168 .6 .10 & 255.255 .255 .0 & 192.168 .6 .15 \\
\hline
\end{tabular}

Pemberian alamat IP address pada setiap router menggunakan Winbox. Contoh pemberian alamat pada router CE1.

\section{PENGUJIAN KONEKTIVITAS}

Pada saat ditambahkan router CE yang lain pada router PE1 dan diuji konektivitasnya, tidak dapat saling terhubung, hal ini disebabkan karena pada router PE1 sudah dibatasi user mana yang dapat masuk ke dalam daerah VPN. Pengujian antar VLAN 10 dan VLAN 10 dengan CE2 berhasil terhubung terbukti menghasilkan 0\% loss, sehingga antar VLAN 10 dengan CE2 dapat saling bertukar data. Berikutnya adalah pengujian konektivitas antar VLAN 20 dan VLAN 20 dengan CE2, pada pengujian ini juga menghasilkan 0\% loss, sehingga antar VLAN 20 dengan CE2 dapat saling bertukar data. Pengujian konetivitas antar VLAN juga saling terhubung karena adanya tag 802.1Q. Hasil pengujian konektivitas VLAN dapat dilihat pada Tabel 3.

- Tabel 3 Pengujian konektivitas

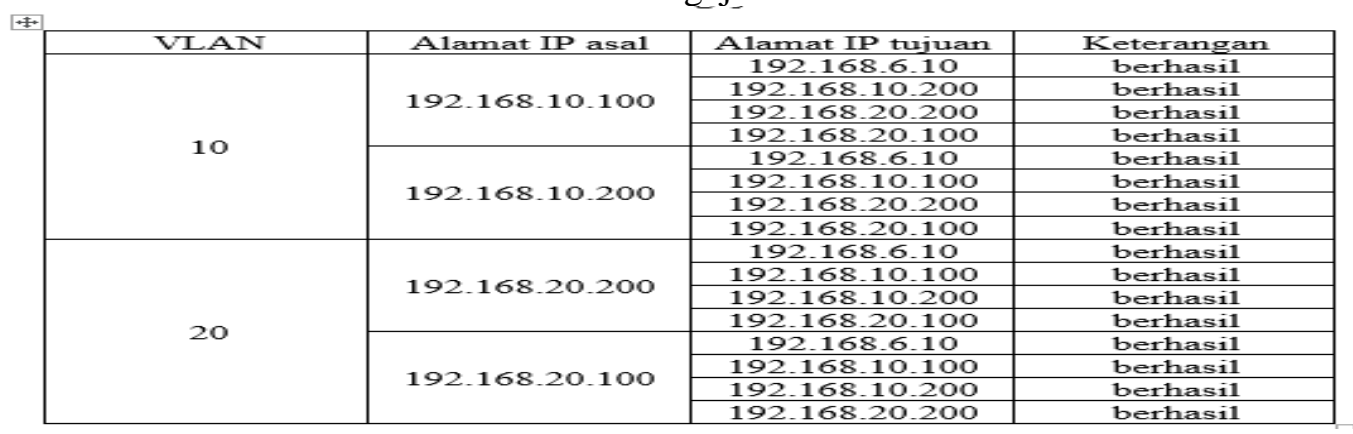




\section{PENGUJIAN ROUTING TABLE}

Pengujian ini menunjukkan informasi yang berisi IP address tujuan. Tabel ini berfungsi agar router dapat menentukan jalur mana yang tercepat untuk mengirimkan data dan bekerja secara dinamik dengan selalu memperbarui tabel routing sehingga jika terjadi suatu kerusakan disalah satu jalur dapat tetap mengirimkan data melalui jalur lain tanpa harus merubah topologi dan konfigurasi. Gambar 9, 10 dan 11 adalah hasil simulasi dari router PE dan P.

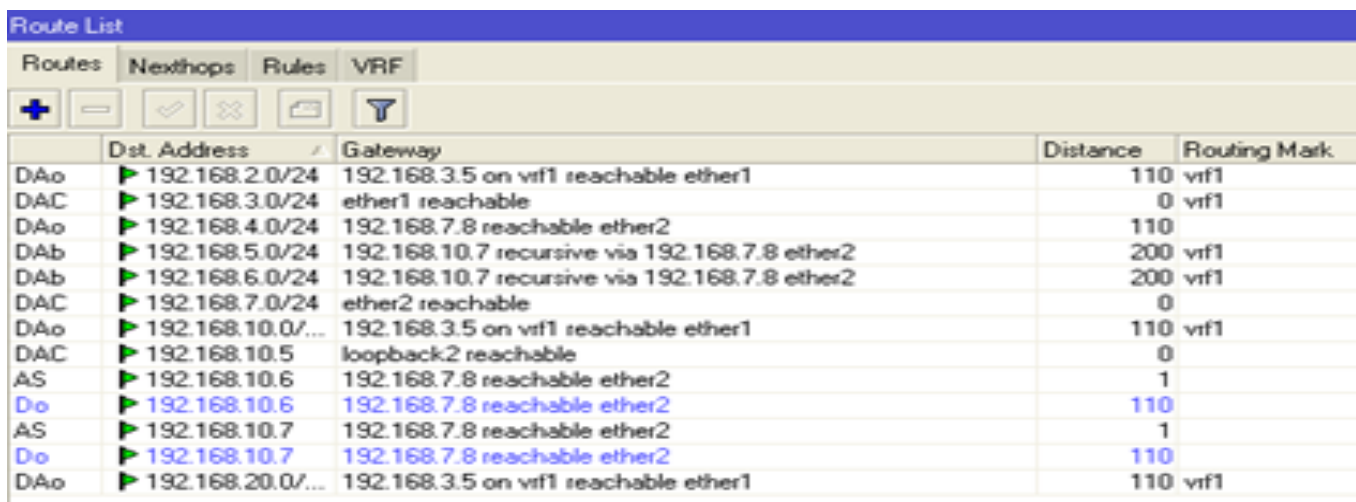

Gambar 9 Tabel Routing pada router PE1

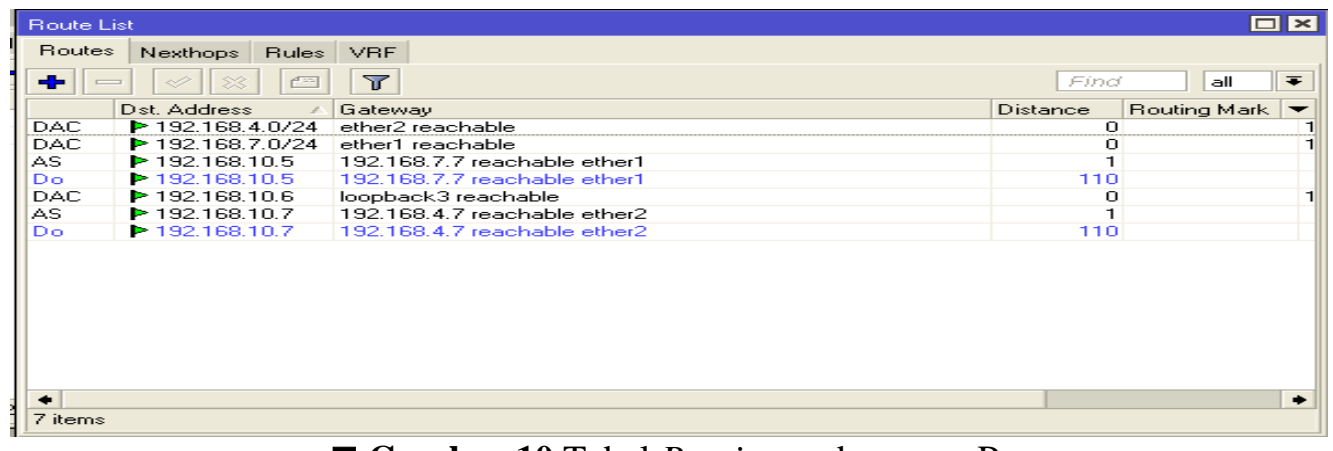

- Gambar 10 Tabel Routing pada router P.

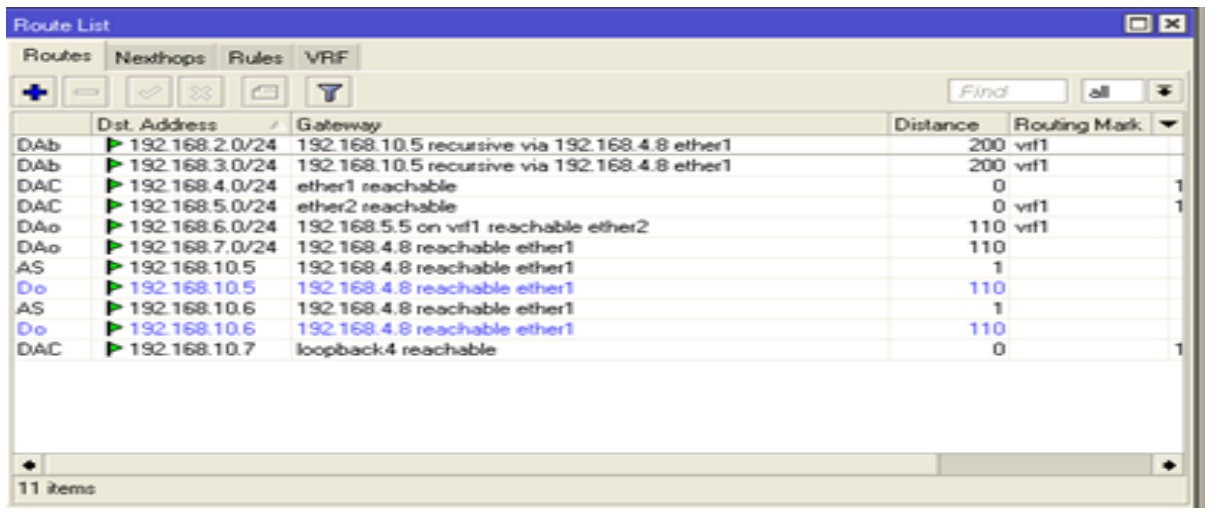

- Gambar 11 Tabel Routing pada router PE2.

\section{PENGUJIAN LABEL MPLS}

Proses pelabelan MPLS pada Gambar 12 menunjukkan pengiriman paket dari salah satu VLAN ke server. Pada paket yang diteruskan, router akan menyisipkan label pada interface yang masuk maupun yang keluar dari router. Saat paket masuk ke CE1, paket disisipkan dengan label 23 menuju PE1. Setelah paket sampai di router PE1, label 23 dilepaskan dan diganti dengan label baru yaitu label 17. Setelah diganti, label akan menuju ke router $\mathrm{P}$. Pada router $\mathrm{P}$, label 17 akan diganti menjadi label 18 dan menuju ke router PE2. Pada saat sampai di router PE2, label 18 akan diganti menjadi label 22 dan menuju router CE2. Pada saat sampai di router CE2 label 22 akan dilepaskan dan paket diteruskan dan menuju ke server. Proses pelabelan dapat dilihat pada Tabel 4. 


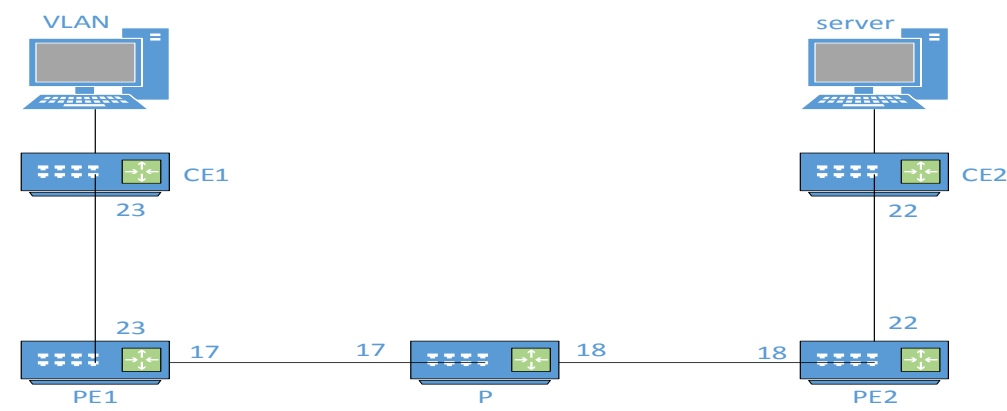

Gambar 12 Pelabelan MPLS

- Tabel 4 Proses pelabelan MPLS

\begin{tabular}{|c|c|c|c|}
\hline Router & In label & Out label & Action \\
\hline CE1 & Ether $1,-$ & Ether 2,23 & Push \\
\hline PE1 & Ether 1,23 & Ether 2,17 & Swap \\
\hline P & Ether 1,17 & Ether 2,18 & Swap \\
\hline PE2 & Ether 1,18 & Ether 2,22 & Swap \\
\hline CE2 & Ether 1,22 & Ether $2,-$ & Pop \\
\hline
\end{tabular}

Pelabelan yang dilakukan MPLS diberikan kepada customer edge yang ingin mengirimkan paket melalui provider edge. Gambar 13, 14 dan 15 adalah hasil pelabelan MPLS pada router PE dan $\mathrm{P}$

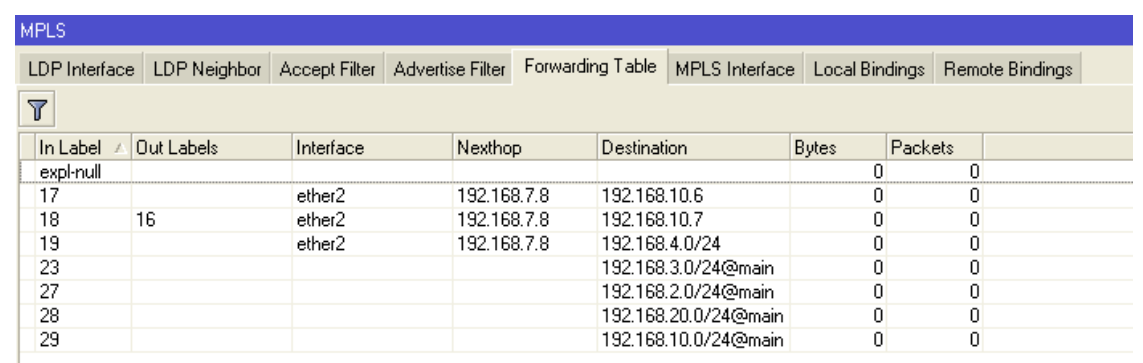

- Gambar 13 Label MPLS pada router PE1.

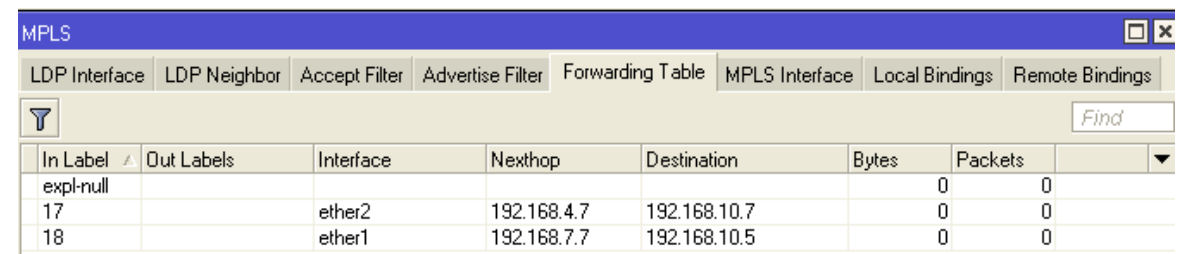

- Gambar 14 Label MPLS pada router P.

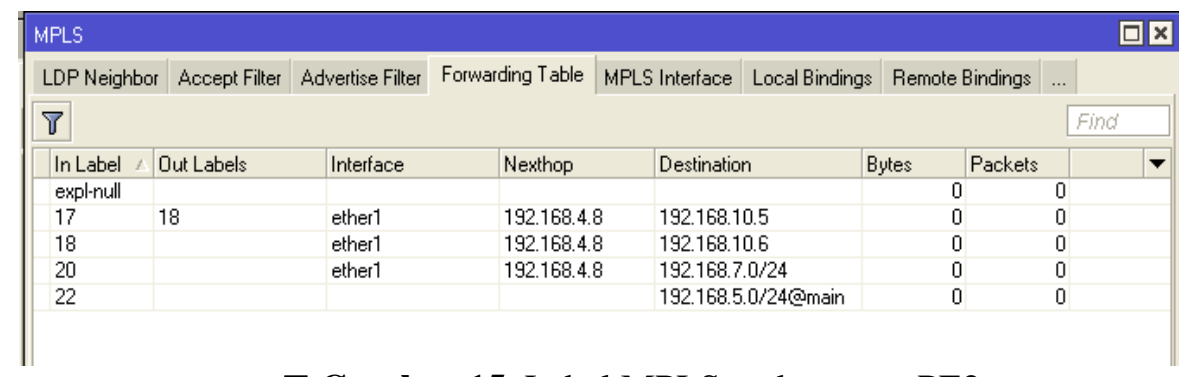

- Gambar 15 Label MPLS pada router PE2.

\section{PENGUJIAN BGP}

BGP akan memberikan alamat prefix pada customer edge agar customer edge dapat masuk dan dapat terhubung dengan provider edge. Gambar 16 adalah hasil pengujian pada router $\mathrm{P}$. 


\begin{tabular}{|c|c|c|c|c|c|c|}
\hline \multicolumn{6}{|l|}{ BGP } & \\
\hline Instances VRFs & is Peers Netw & Norks Aggregate & tes VPN4 Routes & s Advertise & ements & $\square x$ \\
\hline \multicolumn{6}{|l|}{8} & Find \\
\hline Route Disti... & Dst. Address & Gateway & Interface & In Label & Out Label & v \\
\hline $0: 111$ & $192.168 .3 .0 / 24$ & 192.168 .10 .5 & unknown & 24 & 24 & \\
\hline $0: 111$ & $192.168 .2 .0 / 24$ & 192.168 .10 .5 & unknown & 25 & 25 & \\
\hline $0: 111$ & $192.168 .5 .0 / 24$ & 192.168 .10 .7 & unknown & 19 & 19 & \\
\hline $0: 111$ & $192.168 .6 .0 / 24$ & 192.168 .10 .7 & unknown & 21 & 21 & \\
\hline
\end{tabular}

Gambar 16. Pelabelan VPN4 pada router $\mathrm{P}$

\section{PENGUJIAN MPLS TANPA VLAN}

Pada pengujian CE1 tidak menjadi VLAN dan sebagai client dengan CE2 sebagai server menghasilkan bandwidth sebesar rata-rata $16 \mathrm{MBps}$ dan ini ditunjukkan Gambar 17.

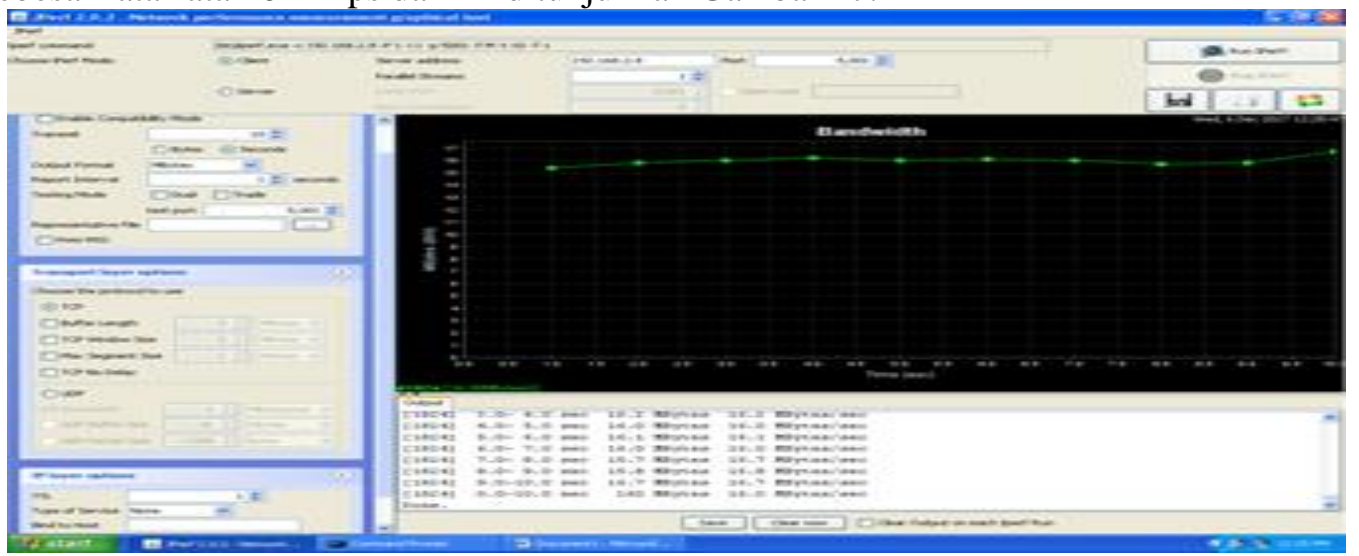

- Gambar 17 Pengujian MPLS tanpa VLAN antara CE2 dengan CE1

\section{PENGUJIAN MPLS DENGAN VLAN}

Pada pengujian VLAN 20 sebagai client dengan CE2 sebagai server menghasilkan bandwidth sebesar rata-rata 11 MBps seperti yang diperlihatkan Gambar 18.

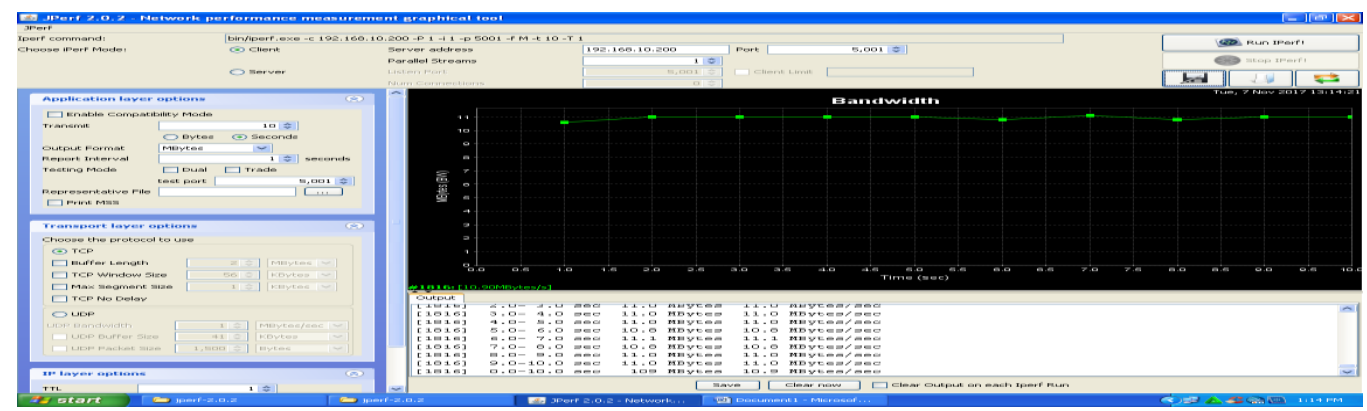

Gambar 18 Pengujian MPLS dengan VLAN antara CE2 dengan VLAN 10 (PC2).

\section{KESIMPULAN}

1. Jaringan MPLS VPN dengan VLAN aman karena terdapat jaringan VPN yang hanya dapat terhubung dengan customer edge tertentu dan jaringan VLAN aman karena dapat memilih VLAN mana yang akan menerima data tanpa perlu mengirim secara broadcast.

2. Pengukuran bandwidth MPLS menggunakan VLAN lebih kecil daripada dengan MPLS tanpa menggunakan VLAN, hal ini karena pada saat menggunakan VLAN bandwidth yang digunakan akan terbagi sesuai dengan kebutuhan setiap PC, sedangkan pada saat tanpa VLAN bandwidth yang digunakan tidak terbagi dan mengirim data secara broadcast.

3. Hasil simulasi menunjukkan VLAN yang berada pada beda VLAN dapat saling berkomunikasi karena adanya tag 802.1Q dan terhubung dengan router 
[1] Allour. 2011. Multi Protocol Label Switching (MPLS), (online) (https://aloriadi.wordpress.com/2011/12/02/multyprotocol-label-switching-mpls/ diakses, 30 November 2017)

[2] David. 2016. Multi Protocol Label Switching - Traffic Engineering menggunakan Router Mikrotik. Skripsi. Jakarta: Program Sarjana Universitas Katolik Indonesia Atma Jaya.

[3] Kun, A. 2009. Konsep VLAN, (online) (https://pekoktenan.wordpress.com/2009/03/23/konsepvlan/comment-page-2/, diakses 29 November 2017)

[4] Musajid, A. 2015. Jaringan Virtual Mikrotik, Cisco, dan Juniper dengan GNS3. Jakarta: Jasakom.

[5] Rahman, M. 2013. VRF (VPN Routing Forwarding) Configuration, (online) (https://belajarcomputernetwork.com/2013/10/07/vrf-virtual-routing-forwarding-configuration/, diakses 29 November 2017)

[6] Ridwan. 2011. Virtual Routing and Forwarding (VRF), (online) (https://ridwannm.wordpress.com/2011/02/12/virtual-routing-and-forwarding-vrf/, diakses 29 November 2017)

[7] Sofana, I. 2012. CISCO CCNP dan Jaringan Komputer Materi Route, Switch, Troubleshooting). Bandung: Informatika Bandung.

[8] Triana, J. 2016. Simulasi Multi Protocol Label Switching Virtual Private Network (MPLS VPN) dengan Router Mikrotik. Skripsi. Jakarta: Program Sarjana Universitas Katolik Indonesia Atma Jaya.

[9] Wiki. $\quad$ Tanpa $\quad$ Tahun. Manual:Interface/VLAN,

[10] Wiki. Tanpa Tahun. SwOS, (online) (https://wiki.mikrotik.com/wiki/SwOS, diakses 4 Desember 2017) 